Mehmet Akif Ersoy Üniversitesi Fen Bilimleri Enstitüsü Dergisi 10(1): 68-72 (2019)

The Journal of Graduate School of Natural and Applied Sciences of Mehmet Akif Ersoy University 10(1): 68-72 (2019)

Araştırma Makalesi / Research Paper

\title{
Wilkinson Güç Birleştirici Kullanarak İki Girişli RF Enerji Hasatlama Devresi ve DC Yük Analizi
}

\author{
Ömer KASAR ${ }^{\mathbb{D} 1}$, Mesud KAHRIMAN ${ }^{\text {DD }}{ }^{2 *}$, Mahmut Ahmet GOZEL ${ }^{\mathbb{D}} 2$ \\ ${ }^{1}$ Artvin Çoruh Üniversitesi, Mühendislik Fakültesi, Artvin \\ ${ }^{2}$ Süleyman Demirel Üniversitesi, Mühendislik Fakültesi, Isparta \\ Geliş Tarihi (Received): 08.04.2019, Kabul Tarihi (Accepted): 27.05.2019 \\ $\square$ Sorumlu Yazar (Corresponding author*): omerkasar@artvin.edu.tr \\ (C) +904662151040 且 +904662151057
}

öz

Kablosuz iletişim sistemlerinden ortama pek çok frekansta sinyaller yayılmaktadır. Enerji hasatlama, ortamdaki bu anlık olarak var olan sinyallerin enerjisini alarak doğru akım ve gerilime dönüştürme işidir. Bu çalışmada, Wilkinson güç birleştirici kullanarak bir enerji hasatlama devresi tasarlanmıştır. Önerilen devre; iki koldan aldığı sinyalleri birleştirerek Greinacher doğrultma devresine aktarmaktadır. Tasarımın merkez frekansı; ISM bandını kapsaması için 2,45 $\mathrm{GHz}$ olarak seçilmiştir. Tasarlanan devrenin Giriş Gücü-Verim ve Giriş Gücü-Çıkış gerilimi analizi yapılmıştır. Ayrıca, yük direncinin değişen değerlerin göre de bu analizler tekrarlanmıştır. Sonuçta en iyi performans; $9 \mathrm{dBm}$ giriş gücü ve 200 Ohm yük direnci için yaklaşık \%68 toplam dönüştürme verimi ve 1 Volt çıkış gerilimi elde edilmiştir.

Anahtar Kelimeler: Enerji Hasatlama, Wilkinson Güç Birleştirici, Greinacher Doğrultucu Devre, Yük Analizi

\section{A Double Input RF Energy Harvesting Circuit Using Wilkinson Power Com- biner and DC Load Analysis of the Circuit}

\begin{abstract}
The signals are emitted from the wireless communication systems to the environment at many frequencies. Energy harvesting is the process of converting the the existing signals to the direct current and voltage by taking the energy. In this study, we designed an energy harvesting circuit using Wilkinson power combiner. The proposed circuit; combines received power from two input arms, and then transmits to the Greinacher Rectifier circuit. The central frequency of the design was selected as $2.45 \mathrm{GHz}$ to cover the ISM band. In the study, input power-efficiency and input poweroutput voltage analysis of the designed circuit were performed. In addition, these analyzes were repeated according to the changing values of the load resistance. After all, the best performance; for $9 \mathrm{dBm}$ input power and $200 \mathrm{Ohm}$ load resistance; approximately $68 \%$ of the total conversion efficiency and 1 Volt output voltage was obtained.
\end{abstract}

Keywords: Energy Harvesting, Wilkinson Power Combiner, Greinacher Rectifier Circuit, Load Analysis

\section{GíRiş}

Radyo frekanslarda (RF) çalışan kablosuz iletişim sistemleri yayıldığı ortama, sinyallerin gücünü taşır. Ortamda mevcut olarak bulunan bu RF güçler, çeşitli elektronik devre ve cihaz uygulamalarında kullanılmak üzere enerji toplayıcı devrelerce alınır, doğrultularak doğru akım ve gerilim (DC) elde edilir. Bu işleme enerji hasatlama işlemi denir (Kasar ve ark., 2019).

Ortamda anlık olarak bulunan RF sinyaller, pek çok kaynaktan ve farklı frekanslardan yayılmaktadır. Enerji

Omer KASAR, https://orcid.org/0000-0003-1859-5236 Mesud KAHRIMAN, https://orcid.org/0000-0003-0731-0936 Mahmut Ahmet GOZEL, https://orcid.org/0000-0002-0360-7188 
hasatlama ile bu sinyalleri dönüştürme ve kullanma işlemi pek çok yönden avantaj sağlayacaktır. Hem kullanım ömrü sınırı ona batarya ve benzeri kaynaklara olan ihtiyacı azaltacaktır, hem de ve bakımı kolay, ömrü uzun ve depolama gerektirmeyen yeni bir enerji kaynağı sağlayacaktır. RF enerji hasadında kullanılan doğrultma devreleri, temel elektronik devre yapılarının pek çok farklı uygulamalarından biridir. Literatürde, ortamdan RF enerji hasatlamak için pek çok devre önerilmiştir. En çok bilinenlerinden bir tanesi de Greinacher doğrultma devresidir. Temelde düşük akım ve gerilimlere cevap verebilen Schottky diyotunu kullanan Greinacher doğrultucu devresi çıkış yükü üzerinde yüksek güç dönüştürme verimi (TDV) ve yüksek DC gerilim elde edilmesini sağlamaktadır (Gozel ve ark., 2019).

Wilkinson güç bölücüler, giriş gücünü iki kola paylaştırmasının yanında iki koldan gelen güçleri de tek bir kolda birleştirebilmektedir. Bu amaçla kullanıldığında Wilkinson güç birleştirme devresi adını alır (WGB) (Pozar, 2005). Bu imkânı sağlamasında en önemli parametre çıkış kollarının giriş; giriş kapısının da çıkış olarak kullanılabilmesidir. Bu özelliği kullanabilmenin şartı, giriş güçlerinin birbirini etkilememesi için izolasyon parametresinin yüksek olmasıdır (Kasar ve ark., 2018; Moulay ve Djerafi, 2018).

Bu çalışmada Wilkinson güç birleştirme (WGB) devresi ile iki girişli bir enerji hasatlama devresi önerilmiştir. Böylelikle birden fazla sinyal kaynağından (anten vb.) gelen güçler, en düşük kayıpla doğrultucu devresine aktarılacaktır. Doğrultucu devre olarak literatürde sıklıkla kullanılan Greinacher RF'ten DC'ye Dönüştürme Devresi (GDD) kullanılmıştır (Kim ve ark., 2014; Chaour ve ark., 2017).

Çalışmanın ikinci kısmında tasarım parametreleri belirtilmiştir. Ayrıca devrenin boyutları ve özellikleri tablo halinde verilmiştir. Tasarımın değerlendirme performanslarından bahsedilmiştir. Tüm tasarımlar üç boyutlu elektromanyetik tasarım programı ADS 2009 üzerinde yapılmıştır.
Üçüncü ve dördüncü kısımda simülasyon sonuçları grafikler halinde verilmiş ve elde edilen sonuçlar değerlendirilmiştir. Önerilen çalışmanın özgünlüğü, tasarım üzerindeki tüm işlemler, sonuçlar ve değerlendirmeler literatürdeki bilimsel gerçeklerle uyuşmaktadır.

\section{DEVRE TASARIMI}

İki eşit koldan gelen RF enerji, Wilkinson güç birleştirici (WGB) devresinin çıkışındaki Greinacher RF'ten DC'ye doğrultma devresine (GDD) aktarmaktadır. WGB ve GDD arasına empedans uyumu için konik bir iletim hattı yerleştirilmiştir.

Wilkinson güç bölücü devresi tek giriş ve birden fazla çıkışlı devrelerdir. Tersinir özelliğinden dolayı çıkış kollarından giren gücün, giriş kapısında toplanabilmesi; bunun Wilkinson güç birleştirici devre olarak kullanılabilmesine olanak sağlamaktadır. WGB'nin temel yapısı; çeyrek dalga boyu uzunluğunda iki koldan giren güç empedans uyumlandırılmış bir iletim hattı ile tek bir çıkışa aktarılmasından ibarettir. Temel devre yapısı, her bir kol için tek-çift mod analizi yardımıyla yapılmaktadır (Kasar ve ark., 2019). Girişte $\mathrm{W}_{1}=50 \Omega$ olan hat empedansı çeyrek dalga empedans uyumlandırma tekniği ile uyumlandırılmıştır. İki giriş kolunun arasına kayıp olmaması için izolasyon direnci $\mathrm{R}_{1}=100 \Omega$ yerleştirilmiştir. Kolların birleştiği noktada hat kalınlığı yine $\mathrm{W}_{2}$ kalınlığındadır.

RF doğrultucu Greinacher devresi FR4 alttaş malzemesi üzerine tasarlanmıştır. Fiyatı ucuz ve temin etmesi kolay olan FR4 alttaş malzemenin elektrik geçirgenliği $\epsilon_{\mathrm{r}}=4,3$ kalınlığı $\mathrm{d}=1,5 \mathrm{~mm}$ ve kayıp tanjantı da $\tan \delta=$ 0,025 'dir. Doğrultucu devrede 4 adet HSMS-285C Schottky diyotu, ikişer ikişer olarak tam dalga doğrultma yaparak 4'lü bir dizi halinde yük direncinin üzerinde $D C$ gerilim oluşmasını sağlamaktadır. $\mathrm{C}_{1}=\mathrm{C}_{2}=1 \mathrm{pF}$ olan kondansatörler de tam dalga doğrultma işleminde dalgalılığı önlemektedir. Doğrultucu devrenin boyutları ile her bir tasarım parametresinin uzunluğu Tablo 1'de verilmiştir.

Tablo 1. Uzunluk ve Parametreleri

\begin{tabular}{|l|c|c|l|}
\hline & Değer & & Değer \\
\hline$W_{1}$ & $2,9 \mathrm{~mm}(50 \Omega)$ & $L_{1}$ & $18,4 \mathrm{~mm}$ \\
\hline$W_{2}$ & $1,6 \mathrm{~mm} \mathrm{(70,7}$ & $L_{2}$ & $16 \mathrm{~mm}$ \\
& $\Omega)$ & & \\
\hline$W_{3}$ & $4,5 \mathrm{~mm}$ & $L_{3}$ & $33 \mathrm{~mm}$ \\
\hline$W_{4}$ & $0,5 \mathrm{~mm}$ & $\epsilon_{r}$ & 4,3 \\
\hline$W_{5}$ & $2,6 \mathrm{~mm}$ & $d$ & $1,5 \mathrm{~mm}$ \\
\hline$W_{6}$ & $5,7 \mathrm{~mm}$ & $\tan \delta$ & 0,025 \\
\hline$W_{7}$ & $11,2 \mathrm{~mm}$ & $f_{0}$ & $2,45 \mathrm{GHz}$ \\
\hline
\end{tabular}


DC gerilimin elde edildiği yük direnci R_2=200 $\Omega$ seçilmiştir. Yük çıkışı alttaş malzemenin altındaki bakır (toprak) tabakaya bağlanmıştır. Yük direncinin seçimi ve parametrik analizi ileride anlatılacaktır. WGB uygulanmış
Greinacher doğrultucu devreye ait devrenin şematik görüntüsü Şekil 1'de gösterilmiştir.

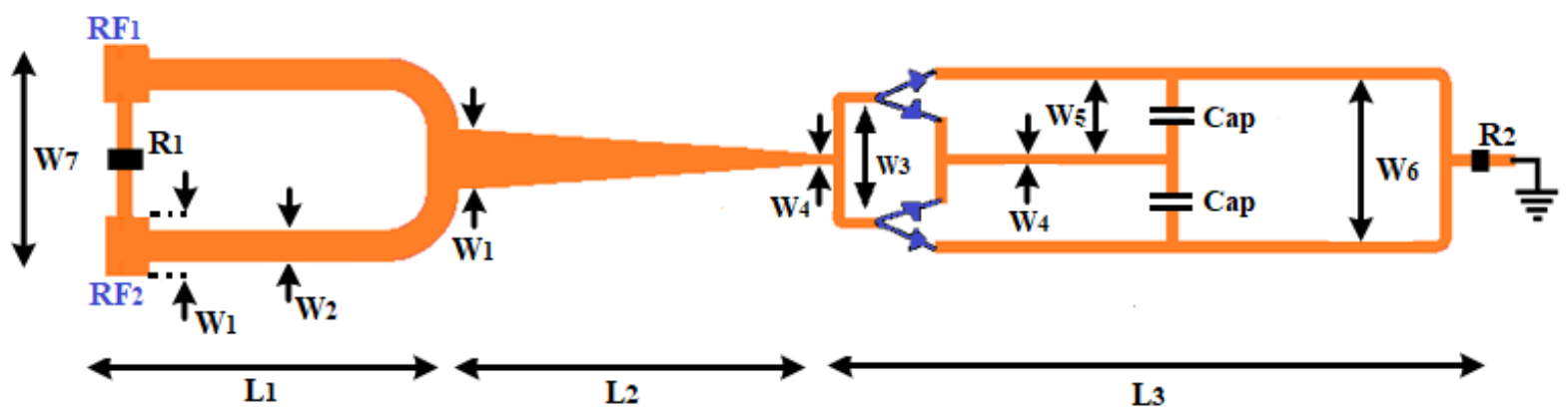

Şekil 1. Wilkinson güç birleştirici uygulanmış Greinacher doğrultucu devresinin şematik görüntüsü

Enerji hasatlamak amacıyla tasarlanan WGB devresi ve GDD devresi $f_{0}=2,45 \mathrm{GHz}$ için tasarlanmıştır. Tüm tasarım boyutları bu frekans üzerinden hesaplanmış ve simülasyonu yapılmıştır. Bir enerji hasatlama devresinde çalışma performansının değerlendirildiği parametreler; çalışma frekansı, toplam güç dönüştürme verimi ve yük direncine göre çıkış gerilimidir (Gozel ve ark., 2019).

Çalışma frekansı Saçılma (S) Parametrelerine göre değerlendirilir. Burada $S_{11}$ ve $S_{22}$ birinci ve ikinci giriş kapılarındaki yansımayı ifade eder. Yani WGB'ye geldiği kapıdan geri dönen gücü ifade eder. Yansıma istenmeyen bir durumdur. Ve düşük olması istenir. Aynı şekilde $S_{12}$ ve $S_{21}$ de giriş portları arasındaki izolasyonun bir ölçütüdür. Yani bir kapıdan giren güç, doğrultucu devresine girmek yerine diğer kapıdan çıkmaya çalışır. Bu çıkış ne kadar düşükse izolasyon kaybı da o kadar düşük olur. İzolasyon katsayısının düşük olması beklenir (Pozar, 2005).

Bir doğrultucu devrenin verimi çıkışta elde edilen DC gücün $\left(P_{\mathrm{DC}}\right)$, devrenin girişinden verilen RF güce $\left(P_{\mathrm{RF}}\right)$ oranıdır. Buna RF'ten DC'ye güç dönüştürme verimi (TDV) denir. Yüzde verim hesaplaması Denklem 1'de verilmiştir. TDV aynı zamanda kapılardan giren gücün ne kadarının alınabildiğinin yüzdelik olarak ifadesidir.

$$
\operatorname{TDV}(\%)=\frac{\mathrm{P}_{\mathrm{DC}}}{\mathrm{P}_{\mathrm{RF}}} \times 100
$$

Burada dikkat edilmesi gereken iki farklı giriş olduğundan çıkışta elde edilen gücün iki girişten sağlanan toplam (iki kat) güçten geldiğinin hesaba katılmasıdır. Bu durumda toplam dönüştürme verimi $\mathrm{N}$ tane giriş kapısı için Denklem 2'den hesaplanabilir.

$$
\operatorname{TDV}(\%)=\frac{\mathrm{P}_{\mathrm{DC}}}{\sum_{1}^{\mathrm{N}} \mathrm{P}_{\mathrm{RF}}} \times 100
$$

Doğru akım ve gerilime dönüştürülen güç bir yük üzerinde tüketilir. Bu yükü temsil etmek için bir direnç kullanılmıştır. Bu yük direnci üzerine düşen gerilim çıkış direnci olarak tanımlanır. Bu çalışmada; WGB devresinin iki farklı girişine, değişen değerlerde güç uygulanmıştır. Seçilen çalışma frekansında iki girişe de aynı güç değeri uygulanmıştır. Doğrultucu çıkışındaki yükte elde edilen verim ve çıkış gerilimi analiz edilmiştir.

\section{BULGULAR}

Eşit iki girişi olan WGB simetrik olduğundan, yansıma parametreleri ve izolasyon parametreleri iki kapı için de eşittir $\left(S_{11}=S_{22}\right.$ ve $\left.S_{12}=S_{21}\right)$ (Pozar, 2005). Şekil 2'de önerilen devrenin $S$ parametreleri grafiği verilmiştir. Her iki parametre için de (yansıma ve izolasyon) referans değeri olarak -20 dB kabul edildiğinde çıkışına GDD uygulanmış WGB devresinin çalışma frekansı 2,42-2,55 GHz aralığındadır. Çalışma aralığı grafikte belirtilmiştir. Bu durumda devrenin, genel olarak ISM bandında yapılacak RF uygulamaları kapsadığı söylenebilir.

Çalışma aralığı belirlenen devreye, merkez frekansı $f_{0}=$ $2,45 \mathrm{GHz}$ olacak şekilde iki koldan da giriş gücü uygulanmıştır. -30 ile $+20 \mathrm{dBm}$ arasında değişen giriş gücü değerlerine göre çıkıştan elde edilen toplam dönüştürme verimi (\%) analiz edilmiştir. Yine, değişen giriş güçlerine göre, başlangıçta seçilen yük direnci $R=200 \Omega$ için çıkış gerilimi analizi yapılmıştır. Şekil 3'te giriş gücüne göre verim (solda) ve çıkış gerilimi (sağda) grafiği görülmektedir. Grafikten de anlaşılacağı gibi giriş gücü $9 \mathrm{dBm}$ olduğunda en iyi verim yaklaşık \% 68 olarak elde edilmiştir. Bu değerden sonra, çıkış gerilimi artsa da edilen verim azalmaya başlamaktadır. 


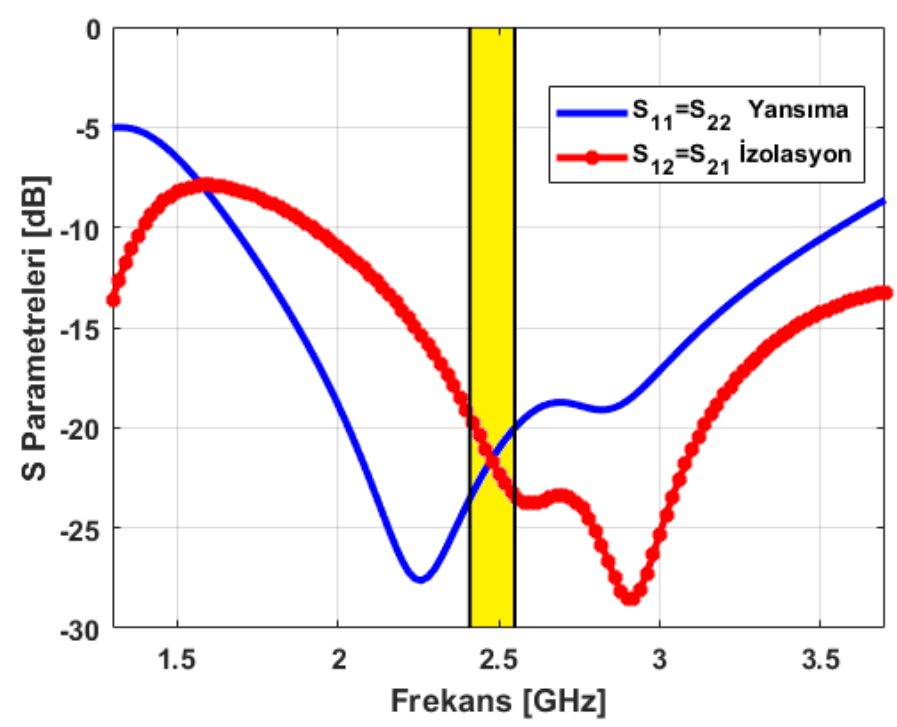

Şekil 2. Önerilen enerji hasatlama devresinin S parametreleri

Bu çalışmanın esasını oluşturan bir diğer parametre de yük analizidir. En iyi verim performansını sağlayan güç değeri referans kabul edilmiştir (9 dBm). Yük direnci parametrik olarak $50 \Omega$ ile $2000 \Omega$ arasında değiştirilmiştir. Değişen direnç değerlerine göre verim önce artmış ve bir noktada en yüksek değerine ulaşmıştır (yaklaşık \% 68). Direnç değeri daha da arttıııldığında verim düşmeye başlamıştır. Bunun yanında çıkış gerilimi yükselmeye devam etse de artış miktarı azalmış ve bir zaman sonra sabitlenmiştir.

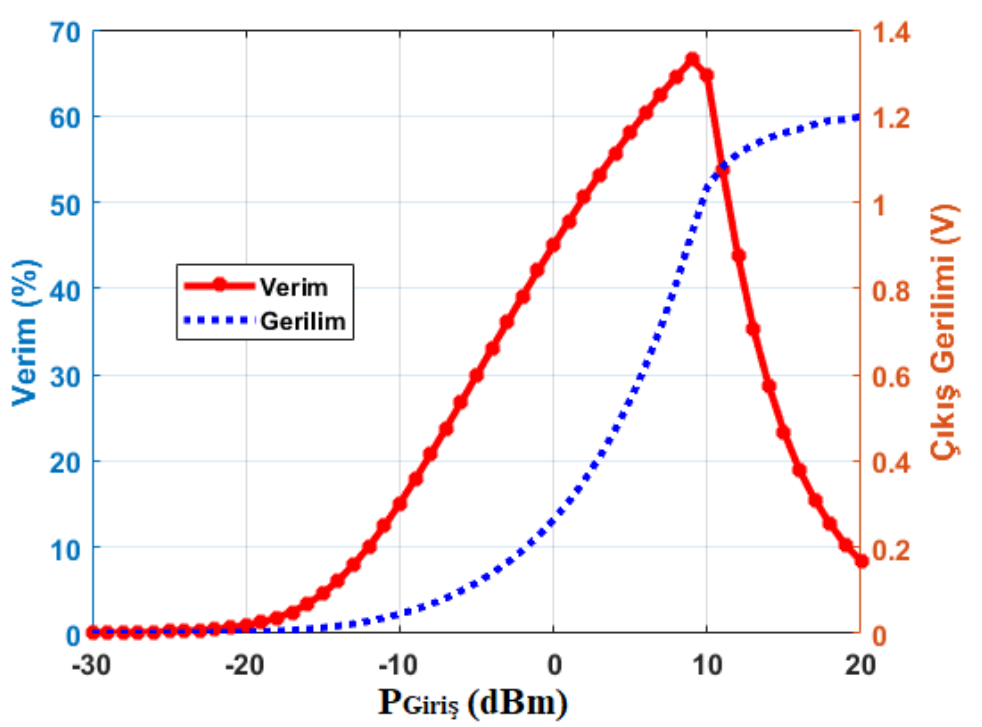

Şekil 3. Giriş gücüne göre verim (solda) ve çıkış gerilimi (sağda)

Şekil 4'te yük direncine göre verim ve çıkış gerilimi analizi görülmektedir. En yüksek verimi veren yük değeri (TDV $=\% 68$ için) $R=200 \Omega$ 'dur. Ve bu direnç değerine göre çıkış gerilimi yaklaşık olarak $V=1$ Volt civarındadır.

Verimin ve çıkış geriliminin değişen güç ve yük direnci değerine göre artıp azalması Greinacher doğrultma devresinin $\mathrm{RF}^{\prime}$ ten $\mathrm{DC}$ 'ye dönüştürebildiği akım miktarı ile doğrudan ilgilidir. Eğer her güç değerinde sabit akımı dönüştürebilseydi; Denklem (1) ve (2)'ye göre yük değeri arttıkça çıkış geriliminin doğrusal bir çizgi şeklinde artması gerekirdi. Tüm bunların yanında; gerilim grafiğinin azalan eğimde devam etmesi, Shottky diyotu doğrusal olmayan bir devre elemanı olmasının bir sonucudur. 


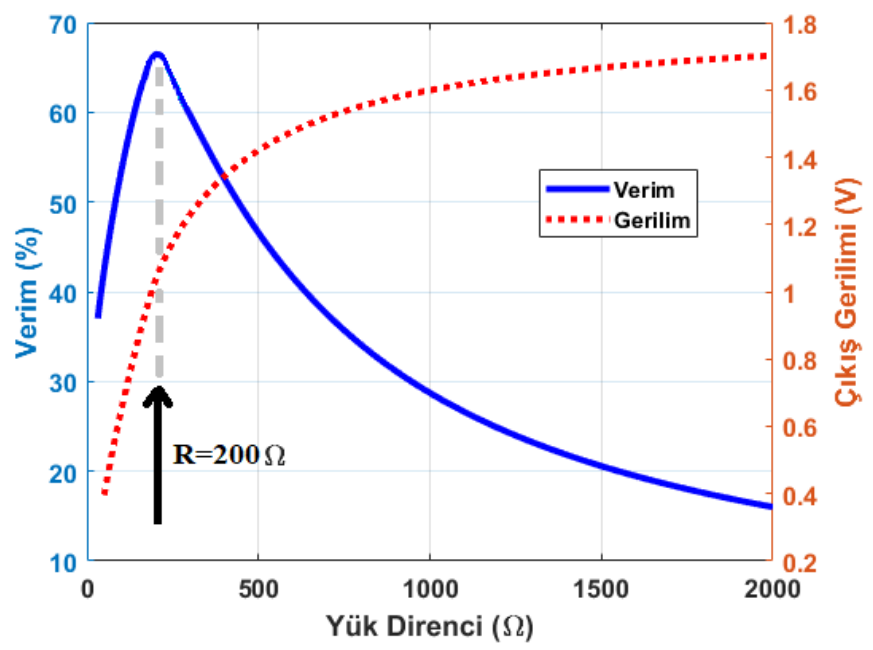

Şekil 4. Yük direncine göre verim (solda) ve çıkış gerilimi (sağda)

\section{SONUÇLAR}

Bu çalışmada Wilkinson güç birleştirici devresi kullanılarak iki girişli bir enerji hasatlama devresi tasarlanmıştır. Greinacher doğrultma devresi kullanılan devrede, değişen giriş güçlerine göre verim ve çıkış gerilimi analizi yapılmıştır.

En iyi performansın elde edildiği giriş gücü değeri referans kabul edilerek sabit giriş gücü için değişen yük direnci analizi yapılmıştır. Yük direncinin artmasıyla verim artmış ve bir noktada maksimum değere ulaşmıştır. Direnç değeri artmaya devam ettiğinde ise verim azalmaya başlamıştır. Şekil 4'te, en yüksek direnç değerinin en yüksek verimi sağlamadığı görülmektedir.

Aynı durum çıkış gerilimi ve verim arasında da söz konusudur. Şekil 3'te, daha yüksek çıkış gerilimin değerlerinin; daha iyi verim performansını vermeyeceği anlaşımaktadır. Bu durum Greinacher doğrultma devresi üzerindeki diyotların doğrusal olmamasına ve doğrultma performansının kısıtlı olmasına bağlanmaktadır. Yük Direnci-Verim ve Yük Direnci-Çıkış Gerilimi analizleri literatürdeki çalışmalarla paralellik göstermektedir.

\section{KAYNAKLAR}

Chaour, I., Fakhfakh, A., Kanoun, O. (2017). Enhanced passive RF-DC converter circuit efficiency for low RF energy harvesting. Sensors, 17(3): 546.

Gozel, M. A., Kahriman, M., Kasar, O. (2019). Design of an efficiency-enhanced Greinacher rectifier operating in the GSM 1800 band by using rat-race coupler for RF energy harvesting applications. International Journal of RF and Microwave Computer-Aided Engineering, 29(1): 1-8. doi:10.1002/mmce.21621

Kasar, O., Gozel, M. A., Kahriman, M. (2018). Broadband Wilkinson power divider based on chebyshev impedance transform method. International Advanced Researches and Engineering Journal, 2(3): 299-303.

Kasar, O., Kahriman, M., Gozel, M. A. (2019). Application of ultra wideband RF energy harvesting by using multisection Wilkinson power combiner. International Journal of RF and Microwave Computer-Aided Engineering, 29(1): 1-8. doi: $10.1002 / \mathrm{mmce} .21600$

Kim, S., Vyas, R., Bito, J., Niotaki, K., Collado, A., Georgiadis, A., Tentzeris, M. M. (2014). Ambient RF energy-harvesting technologies for self-sustainable standalone wireless sensor platforms. Proceedings of the IEEE, 102(11): 16491666.

Moulay, A., Djerafi, T. (2018). Wilkinson Power Divider With Fixed Width Substrate-Integrated Waveguide Line and a Distributed Isolation Resistance. IEEE Microwave and Wireless Components Letters, 28(2): 114-116.

Pozar, D. M. (2005). Microwave Engineering 3e (3rd ed.). USA: John Wiley and Sons,Inc. 